International Journal of Zoological Investigations

Contents available at Journals Home Page: www.ijzi.net

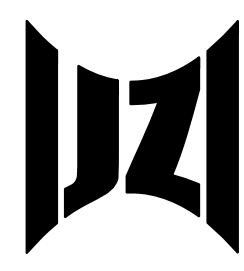

ISSN: 2454-3055

\title{
Feeding Responses of Cotesia plutellae (Kurdjumov) (Hymenoptera: Braconidae) Adults to Honey and Sucrose
}

\section{Kapinder}

Department of Zoology, D. D. U. Gorakhpur University, Gorakhpur 273009, Uttar Pradesh, India

Received: $10^{\text {th }}$ December, 2019

Accepted: $12^{\text {th }}$ January, 2020

Published online: $13^{\text {th }}$ February, 2020

https://doi.org/10.33745/ijzi.2020.v06i01.002

\begin{abstract}
Present study was done to evaluate feeding behaviour of Cotesia plutellae, a larval parasitoid of diamondback moth, towards honey and sucrose under laboratory conditions. On allowing access to honey, sucrose or sucrose in the midst of honey vapour in feeding chamber, female wasps reached to honey directly without preceding random movements. But they took longer to reach sucrose after random movements. Male wasps took longer time than females to reach honey and much longer to reach sucrose after prolonged random movements. Sucrose in the midst of honey vapour was found and fed upon in almost same time as honey alone. Although a high percentage of wasps fed on honey, sucrose and sucrose in honey vapour, total duration of feeding of females on honey was longer than that on sucrose but it further extended when sugar was provided in the midst of honey vapour. Males fed on these foods for shorter durations than females. Implications of this study in using honey as a food source for biological control are discussed.
\end{abstract}

Keywords: Cotesia, Feeding response, Honey odour, Sucrose

Citation: Kapinder: Feeding responses of Cotesia plutellae (Kurdjumov) (Hymenoptera: Braconidae) adults to honey and sucrose. Intern. J. Zool. Invest. 6 (1): 21-30, 2020. https://doi.org/10.33745/ijzi.2020.v06i01.002

\section{Introduction}

Hymenopterous parasitoids have been reported to require adequate nourishment in adult stage to survive, produce eggs, move about to forage and parasitize their host insects (Jervis and Kidd, 1986; Takasu and Lewis, 1993, 1995; Heimpel et al., 1997; Lewis et al., 1998; Costamagna and Landis, 2004; Wäckers, 2005). In nature, some adult parasitoids feed on their host insects (Jervis and Kidd, 1986; Heimpel and Collier, 1996; Jervis et al., 1996) whereas many others feed on non-host food sources such as nectar from nectaries and honeydew on various plants (Zobelein, 1955; Leius, 1967; Jervis and Kidd, 1986; Idris and Grafius, 1995; Jervis et al., 1996; Wäckers et al., 1996; Wäckers and Steppuhn, 2003; Wäckers, 2005, Zhou et al, 2012). Food provided to various parasitic 
hymenopterans reared or maintained in insectaries and laboratories includes honey and sugars, particularly sucrose. Different food sources have been reported to differ in their influence on longevity, fecundity, mobility and host-foraging activity of various parasitoids (Leius, 1961a, b; Hagley and Barber, 1992; Mitsunaga et al., 2004; WittingBissinger et al., 2008, Mashal et al., 2019). The food sources that enhance these life processes of parasitoids can be manipulated appropriately for boosting their populations on pest-infested crops to increase parasitization and suppression of their host pest populations.

Trials conducted for manipulating food sources of various parasitoids have been reviewed by Wade et al. (2008b), discussing their successes and limitations. Two main approaches have been followed for such manipulations-- (i) growing in the vicinity of pest-infested crops such non-crop plants as are rich in floral / extra-floral nectaries or homopteran honeydew which serve as nutritious food sources for adult parasitoids; and (ii) applying appropriate artificial food supplements consisting of one or more nutrients like sugars, proteins, etc., to pestinfested crop plants or to neighboring noncrop plants. In both these approaches, parasitoids can readily move between food sources and pest-infested crops, obtaining nourishment from the former and parasitizing their hosts on the latter. The first of these approaches has a limitation that non-crop plants bearing food sources of parasitoids may not be synchronous in time and space with host pests and their crop plants in appropriate stage (Heimpel and Jervis, 2005, Wade et al., 2008 b). Under such circumstances, applying an artificial food supplement to pest infested crop plants or to non-crop plants in its vicinity is desirable. Artificial food supplements so used in some trials include sugars, particularly sucrose (Canäs and O’Neil, 1998) and honey alone (Takasu and Lewis, 1995), or in combination with other nutrients (Wade et al., 2008 a).

In order to choose an appropriate food supplement for adult parasitoids, its nutritional as well as sensory properties need to be taken into consideration. The nutritional properties include nutrient composition of food and its utilizability for parasitoids whereas its sensory properties include the sensory stimuli. Nutritional properties can play their role only after a food supplement is found and fed upon by parasitoids. Finding and feeding on a food supplement is determined by its sensory stimuli some of which (olfactory, visual) are perceived by parasitoids at a distance whereas others (gustatory stimuli) are detected by them after contact with the food. Distance-detectable stimuli from a food source may elicit orientation response of a parasitoid involving its attraction to or repulsion from the food source. If these stimuli attract the parasitoid, it moves to the food source. After contact with the food, if its gustatory stimuli are phagostimulatory, the parasitoid responds by feeding on it. Thus, a food supplement with attractants and phagostimulants is likely to be found and fed upon by parasitoids earlier, thereby minimizing the risk of death due to starvation, than a food source that lacks attractants and can be found by the parasitoids by chance during their random searching movements. 
Nectar-bearing flowers of some plants have been reported to emit odours which attract naïve adults of various parasitoids (Wäckers and Swaans, 1993; Stapel et al., 1997: Wäckers, 2004) as well as those having prior experience of associating those odors with food (Takasu and Lewis, 1993, 1996; Siekmann et al., 2004). Among the artificial food supplements like sucrose and honey, sucrose does not attract any parasitoid but acts as a strong phagostimulant (Wäckers, 1999; Winkler et al., 2006) and is fed upon readily when it comes in contact with the parasitoid.

Honey drops applied to corn and soybean plants were found and fed upon rapidly by unfed females of the parasitoid Microplitis croceipes, previously conditioned by exposure to honey (Takasu and Lewis, 1995). These females might have been attracted to honey by its odour due to prior conditioning though such an attraction was not reported. Males and females of another parasitoid, Pimpla alboannulatus, were reported (Sato and Takasu, 2000) to show flight response indicating their attraction to honey odour in a wind tunnel after they were conditioned to its odour by feeding on honey for three days. Some naive females, but not males, also showed flight response to honey odour.

There is hardly any report of innate attraction of naive hymenopterous parasitoids to honey odour. During our study of orientation responses of Cotesia plutellae adults to odours from various food sources, we observed that naive adult wasps were attracted to honey odour (Kapinder et al., 2019) from a distance in T-tunnel. Present work was therefore taken up to study feeding responses of this parasitoid to honey and compared them with those to sucrose.

\section{Materials and Methods}

Insects

A culture of Cotesia plutellae was maintained on diamondback moth (DBM), Plutella xylostella, in the laboratory at $25 \pm 1 \mathrm{C}$ under $65 \pm 5 \%$ R.H. and 14L: 10D photoperiod. DBM larvae parasitized by C. plutellae were initially collected from cauliflower field and reared on its leaves. Adult wasps, obtained from the parasitized DBM larvae, were provided 50\% honey solution as food and second instar diamondback moth larvae were provided to female in an oviposition chamber $(20 \times 20 \times$ $20 \mathrm{~cm}$ ) for parasitization. These larvae were then transferred to rearing jars and provided cauliflower leaves to continue the culture.

For each test, required number of parasitoid pupae were taken from the culture and kept one each in a glass vial $(60 \mathrm{~mm}$ long, $15 \mathrm{~mm}$ dia). Virgin, water satiated and fooddeprived wasps were used for various tests within 4-8 $\mathrm{h}$ of their emergence. All tests were carried out in a odour free room having exhaust facility and maintaining $25 \pm 1 \mathrm{C}$ temperature and $65 \pm 5 \%$ R.H.

Tests for feeding responses

Feeding responses of the wasps were tested in a rectangular glass chamber $(75 \mathrm{~mm}$ long, 27 mm wide, $25 \mathrm{~mm}$ high) (Fig. 1). One of the two longer vertical walls $(75 \times 25 \mathrm{~mm})$ of the chamber had in its middle an opening $(25 \times 25$ $\mathrm{mm}$ ) which could be closed with a removable, equal sized glass flap. The bottom and top walls were each made of a glass strip $(45 \mathrm{~mm}$ long, $27 \mathrm{~mm}$ wide) in the middle, flanked on either side by two shorter strips (15 mm long, 
$27 \mathrm{~mm}$ wide each) of nylon net (12 mesh/cm). The chamber was supported on two small bakelite cups (12 $\mathrm{mm}$ id, $10 \mathrm{~mm}$ depth) placed one under each bottom net strip.



Fig. 1: Schematic representation of feeding chamber to study feeding response.

The food presented to wasps was honey, sucrose or sucrose in honey vapour. Honey and sucrose were presented as 50\% and $1 \mathrm{M}$ solutions respectively, $0.3 \mathrm{ml}$ of each on a cotton-wool swab $(\approx 6 \mathrm{~mm} \mathrm{dia})$. A single such food swab on a small glass strip (5 $55 \mathrm{~mm}$ ) was placed in the feeding chamber on the bottom net strip of one side. For presenting sucrose in honey vapour, a sucrose swab was placed inside the chamber on one net strip and a honey swab in the cup beneath this strip.

For each test, a wasp was released in the middle of the feeding chamber through its opening, 60-65 s after placing a food swab in position. The opening was then promptly closed with the flap. The wasp was observed continuously for $15 \mathrm{~min}$ for its behavioural responses. Thereafter, the next wasp was tested using freshly prepared honey or sucrose swabs, interchanging their positions each time on the two bottom net strips in the feeding chamber. Each test was repeated with 50 wasps arranged in 5 replicates of 10 each.

\section{Data Analysis}

Responses of wasps to materials in vial $\mathrm{A}$ were compared with those to materials in vial B in T-tunnel bioassays using Student's t test for paired samples. Two-way ANOVA followed by Tukey's HSD test, if required, was used to compare responses of wasps in the feeding chamber among different sexes and food swabs. All the statistical analyses were carried out using the computer program SigmaStat 2.0 (Jandel, 1995).

\section{Results}

When females were released singly in the feeding chamber having a honey swab on one of the bottom net strips, each wasp turned and walked directly to the swab with very little, if any, preceding random movement. Average time taken by the wasps to reach the swab was $7 \mathrm{~s}$ (Table 1). Males, however, walked about randomly for a short time after release and the average time taken by them to reach the honey swab was significantly longer (17.6 s) than that taken by the females. When these male and female wasps were about $10 \mathrm{~mm}$ from the honey swab they started antennating on the net strip while approaching the swab.

When a swab of sucrose instead of honey was placed in the chamber, the females released in its middle moved about randomly in various directions for varying distances and took an average time of $85.8 \mathrm{~s}$ (Table 1) to reach the sucrose swab by chance. Thus, the time taken by these wasps to reach sucrose swab was significantly longer than that taken to reach honey swab. When the antennae touched the sucrose swab, the wasps stopped, started antennating and feeding on it. Male wasps also walked about randomly but for still longer a time (224.2 s) before reaching the sucrose swab, antennating and feeding on it.

In tests with a sucrose swab in the midst of honey vapour, the females reached the 
Table 1: Responses of C. plutellae adults to three types of food swabs, each impregnated with honey, sucrose or sucrose in honey vapour in the feeding chamber.

\begin{tabular}{|c|c|c|c|c|}
\hline \multirow[b]{2}{*}{ Response parameters } & \multirow[b]{2}{*}{ Sex } & \multicolumn{3}{|c|}{ Food on cotton-wool swabs } \\
\hline & & Honey & Sucrose & $\begin{array}{c}\text { Sucrose in } \\
\text { honey vapour }\end{array}$ \\
\hline \multirow{2}{*}{$\begin{array}{l}\text { Time (sec) taken by wasps for first visit } \\
\text { to the food swab }\end{array}$} & Females & $7.0 \pm 0.9 \mathrm{aA}$ & $85.8 \pm 1.8^{\mathrm{aB}}$ & $8.6 \pm 0.4^{\mathrm{aA}}$ \\
\hline & Males & $17.6 \pm 2.2^{\mathrm{bA}}$ & $224.2 \pm 11.8^{\mathrm{bC}}$ & $30.5 \pm 2.3^{\mathrm{bB}}$ \\
\hline \multirow{2}{*}{$\begin{array}{l}\text { \% wasps reaching and feeding on the } \\
\text { food swab }\end{array}$} & Females & $98.0 \pm 2.0^{\mathrm{aA}}$ & $90 \pm 4.5^{\mathrm{aA}}$ & $100 \pm 0.0^{\mathrm{aA}}$ \\
\hline & Males & $90.0 \pm 4.5^{\mathrm{aAB}}$ & $86 \pm 2.4^{\mathrm{aB}}$ & $100 \pm 0.0^{\mathrm{aA}}$ \\
\hline \multirow{2}{*}{$\begin{array}{l}\text { Number of feeding bouts } \\
\text { in } 15 \text {-min periods }\end{array}$} & Females & $1.2 \pm 0.1^{\mathrm{aB}}$ & $0.96 \pm 0.04^{\mathrm{aC}}$ & $2.3 \pm 0.1^{\mathrm{aA}}$ \\
\hline & Males & $1.0 \pm 0.07 \mathrm{bB}$ & $0.9 \pm 0.02^{\mathrm{aB}}$ & $1.2 \pm 0.02^{\mathrm{bA}}$ \\
\hline \multirow[t]{2}{*}{ Duration (secs)of first feeding bout } & Females & $45.8 \pm 0.9 \mathrm{aB}$ & $37.6 \pm 2.2^{\mathrm{aB}}$ & $64.4 \pm 5.1^{\mathrm{aA}}$ \\
\hline & Males & $21.6 \pm 0.8^{\mathrm{bB}}$ & $30.7 \pm 1.1^{\mathrm{aA}}$ & $32.9 \pm 2.4^{\mathrm{bA}}$ \\
\hline \multirow{2}{*}{$\begin{array}{l}\text { Duration (secs) of all feeding bouts in } \\
15 \text {-min periods }\end{array}$} & Females & $47.9 \pm 1.0^{\mathrm{aB}}$ & $38.5 \pm 1.6^{\mathrm{aC}}$ & $90.9 \pm 4.4^{\mathrm{aA}}$ \\
\hline & Males & $22.5 \pm 0.7^{\mathrm{bB}}$ & $30.7 \pm 1.1^{\mathrm{bA}}$ & $35.2 \pm 2.6^{\mathrm{bA}}$ \\
\hline
\end{tabular}

Note: Mean values followed by different lower case letters in a column within the same food and response categories show significant differencesbetween the two sexes whereas mean values followed by capital letters in a row within the same sex and response categories show significant differences between the foods. 
sucrose swab in almost the same time (8.6 s; Table 1) as the honey swab (7 s). This time was significantly shorter than the time (85.8 s) taken to reach sucrose swab alone. Time taken by males to reach the sucrose swab in honey vapour was significantly longer (30.5 s) than that to reach honey alone (17.6 s) but much less than the time (224.2 s) taken to arrive at the sucrose swab alone.

The female wasps that reached and fed on the food swabs during 15-min observation periods ranged from $90 \%$ to $100 \%$ for all three types of food swabs, there being no significant difference among them (Tables 1, 2; 2-way ANOVA followed by Tukey's HSD test, $P>0.05$ ). However, the percentage of males reaching and feeding on the sucrose swab alone (86\%; Table 1) was significantly lower than that (100\%) on sucrose swab in honey vapour but not significantly different from the percentage (90\%) feeding on the honey swab alone. For each of the three types of food

Table 2: Two-way ANOVA Summary on responses of $C$. plutellae adults to three types of food swabs, each bearing honey, sucrose or sucrose in the midst of honey vapour.

\begin{tabular}{|c|c|c|c|c|}
\hline Source of variation & $d f$ & MS & F-value & P-value \\
\hline \multicolumn{5}{|c|}{$\begin{array}{l}\text { Time taken by wasps to reach the food } \\
\text { swabs }\end{array}$} \\
\hline Between food swabs & 1 & 80.18 & 297,68 & $<0.001$ \\
\hline Between sexes & 2 & 231.55 & 859.65 & $<0.001$ \\
\hline Food swabs $\mathrm{x}$ sex interaction & 2 & 11.66 & 43.29 & $<0.001$ \\
\hline Error & 24 & & & \\
\hline \multicolumn{5}{|c|}{$\begin{array}{l}\%^{\text {a }} \text { wasps reaching and feeding on the food } \\
\text { swabs }\end{array}$} \\
\hline Between food swabs & 1 & 0.328 & 2.82 & 0.11 \\
\hline Between sexes & 2 & 0.985 & 8.46 & $<0.002$ \\
\hline Food swab x sex interaction & 2 & 0.111 & 0.96 & $<0.39$ \\
\hline Error & 24 & & & \\
\hline \multicolumn{5}{|c|}{$\begin{array}{l}\text { Number of feeding bouts }{ }^{b} \text { in } 15-\text { min } \\
\text { periods }\end{array}$} \\
\hline Between food swabs & 1 & 0.183 & 71.96 & $<0.001$ \\
\hline Between sexes & 2 & 0.248 & 97.59 & $<0.001$ \\
\hline Food swab x sex interaction & 2 & 0.074 & 29.22 & $<0.001$ \\
\hline Error & 24 & & & \\
\hline \multicolumn{5}{|l|}{ Duration of first feeding bout } \\
\hline Between food swabs & 1 & 3276.08 & 101.06 & $<0.001$ \\
\hline Between sexes & 2 & 724.24 & 22.34 & $<0.001$ \\
\hline Food swab x sex interaction & 2 & 402.73 & 12.42 & $<0.001$ \\
\hline Error & 24 & & & \\
\hline \multicolumn{5}{|c|}{$\begin{array}{l}\text { Duration of all feeding bouts In 15-min } \\
\text { periods }\end{array}$} \\
\hline Between food swabs & 1 & 6571.2 & 249.91 & $<0.001$ \\
\hline Between sexes & 2 & 2646.01 & 100.63 & $<0.001$ \\
\hline Food swab x sex interaction & 2 & 1468.91 & 55.87 & $<0.001$ \\
\hline Error & 24 & & & \\
\hline
\end{tabular}

a,b Data values transformed into square root $x^{1 / 2}$ or $(x+0.5)^{1 / 2}$, respectively. 
swab, the percentage of wasps reaching and feeding on it did not significantly differ between the two sexes (Tables 1, 2; 2-way ANOVA followed by Tukey's HSD test, $P>0.05$ ).

The number of times a wasp fed on the food swabs ranged from 1-3. The average number of feeding bouts per female wasp on the sucrose swab in honey vapor was highest (2.3; Table 1) and significantly different from that on honey (1.2) and sucrose (0.9) swabs alone. Differences between the last two food swabs were also significant. Males, too, had a significantly greater number of feeding bouts on the sucrose swab in honey vapour (1.2; Table 1) than on the honey (1.0) or sucrose (0.9) swab alone. Differences were also significant between the two sexes in the number of their feeding bouts on the honey swab alone and sucrose swab in honey vapour but not on sucrose swab alone.

The duration for which a wasp fed the first time differed among the three types of food swabs (Tables 1,2). The females fed longest on the sucrose swab in honey vapour (64.4 s; Table 1), followed by honey (45.8 s) and sucrose ( $37.6 \mathrm{~s}$ ) swabs alone. Durations of the first feeding bout on the honey and sucrose swabs were statistically the same but significantly shorter than on sucrose swab in honey vapour (Tables 1,2; 2-way ANOVA, HSD test, $P<0.05)$. The males fed for a significantly longer duration on the swabs of sucrose (30.7 s; Table 1) and sucrose in honey vapour (32.9 s) than on the honey swab (21.6 s). However, differences between the two sexes in the duration of their feeding on the honey swab (45. 8s for females and 21.6s for males; Table 1) as well as the sucrose swab in honey vapour (64.4 s for females and $32.9 \mathrm{~s}$ for males; Table 1) were statistically significant but not for feeding on the sucrose swab alone (37.6 for females and 30.7 for males).

Total duration of all feeding bouts during 15-min observation periods was slightly greater than that of the first feeding bout but differences between the food swabs were more or less similar to those of the first feeding bout (Table 1).

\section{Discussion}

In spite of the differences in time taken by males and females of $C$. plutellae to find different food swabs in the feeding chamber, the percentage of wasps reaching and feeding on these swabs was high (86-100\%). It would be so because movements of the wasps were confined within the small closed chamber, and in such condition most wasps would arrive even on the unattractive sucrose swab by chance in the course of their random movements. However, in open fields, the wasps would have a large area to move about and might take much longer time to reach the food. Even then, as in the feeding chamber, the wasps would most likely find honey because of its attraction earlier than unattractive sucrose which may or may not be found in time to avoid starvation death. However, studies of Htet and Uenothe (2019) showed that time taken by parasitoid Itoplectis naranyae to reach sucrose and honey did not differ significantly.

The wasps that arrived and fed on a food swab in the feeding chamber ingested the food in an amount determined by the number and duration of their feeding bouts in the test period. Although female wasps arrived on a sucrose swab much later than on a honey swab, the first feeding bout on both the swabs was statistically equal. However, the number of feeding bouts and their combined duration 
during the entire test period were significantly greater on the honey swab than on the sucrose swab. Consequently, quantitative intake of the honey solution (50\%) would be expected to be more than that of the sucrose solution (1M) within the test period. In this respect, $C$. plutellae females were somewhat similar to those of another parasitoid, Binodoxys communis, which was reported (Wyckhuys et al., 2008) to feed on honey for a much longer time than on $50 \%$ sucrose solution during their first feeding bout. Higher intake of honey solution than of sucrose solution by $C$. plutellae females could contribute, in addition to its nutritional value, to their longer survival on honey than on sucrose (Mitsunaga et al., 2004).

The tests in the feeding chamber also showed that the number and duration of feeding bouts of $C$. plutellae females on a sucrose swab in the midst of honey vapour were almost two times than those on sucrose alone. These observations indicate that honey odour increased the quantitative intake of sucrose solution by female wasps. No such influence was observed in male wasps.

\section{Conclusion}

The present study suggests that it may be helpful in biological control with C. plutellae to use honey as a food supplement before releasing them in the field. Providing honey odour or other experienced odour in the background of an appropriate, and nutritionally efficient food like sucrose or a formulation of various nutrients (Wade et al., 2008 b) which may itself be unattractive to the parasitoids would attract and bring the parasitoids to the proximity of the food. It ultimately increases the parasitisation in the pest infested field; otherwise parasitoid has to devote its time for searching the food for longer distances.

\section{Acknowledgement}

The author is thankful to University Grant Commission, New Delhi for providing financial support for this study.

\section{References}

Canäs LA and O'Neil RJ. (1998) Applications of sugar solutions to maize, and the impact of natural enemies on fall armyworm. Int. J. Pest Manag. 44: 59-64.

Costamagna AC and Landis DA. (2004) Effect of food resources on adult Glyptapanteles militaris and Meteorus communis (Hymenoptera: Braconidae), parasitoids of Pseudaletia unipuncta (Lepidoptera: Noctuidae). Environ. Entomol. 33: 128-137.

Hagley EAC and Barber DR. (1992) Effect of food sources on the longevity and fecundity of Pholetesor ornigis (Weed) (Hymenoptera: Braconidae). Can. Entomol. 124: 341-346.

Heimpel GE and Collier TR. (1996) The evolution of host feeding behaviour in insect parasitoids. Biol. Rev. 71: 373-400.

Heimpel GE and Jervis MA. (2005) Does floral nectar improve biological control by parasitoids? In: Wäckers, F. L. van Rijn, P. C. J., Bruin, J. (Eds.), Plantprovided food for carnivorous insects: a protective mutualism and its applications. Cambridge University Press, Cambridge, pp. 267-304.

Heimpel GE, Rosenheim JA and Kattari D. (1997) Adult feeding and lifetime reproductive success in the parasitoid Aphytis melinus. Ent. Exp. Appl. 83: 305315.

Htet YM and Ueno T. (2019) Effect of sugar food type and concentration on feeding behavior and life expectancy of a parasitoid wasp (Hymenoptera: Ichneumonidae). J. Entomol. Zool. Stud. 7: 17-21.

Idris AB and Grafius E. (1995) Wild flowers as nectar sources for Diadegma insulare (Hymenoptera: Ichneumonidae), a parasitoid of diamondback moth (Lepidoptera: Yponomeutidae). Environ. Entomol. 24: 1726-1735.

Jervis MA and Kidd NAC. (1986) Host feeding strategies in hymenopteran parasitoids. Biol. Rev. 61: 395-434.

Jervis MA, Kidd NAC and Heimpel GE. (1996) Parasitoid adult feeding behaviour and biocontrol- a review. Biocont. News Inform. 17: 11-26. 
Kapinder, Tarkeshwar, Kumar A and Singh AK. (2019) Orientation and behavioural responses of Cotesia plutellae (Kurdjumov) (Hymenoptera: Braconidae) towards honey and sucrose. Intern. J. Zool. Invest. 5: 33-48.

Leius K. (1961 a) Influence of food on fecundity and longevity of adults of Itoplectis conquisitor (Say) (Hymeooptera: Ichneumooidae). Can. Entomol. 93: 771-780.

Leius K. (1961 b) Influence of various foods on fecundity and longevity of adults of Scambius buolianae (Htg.) (Hymenoptera: Ichneumonidae). Can. Entomol. 93: 1079-1084.

Leius K. (1967) Food sources and preferences of adults of a parasite Scambius buolianae (Hymenoptera: Ichneumonidae) and their consequences. Can. Entomol. 99: 865-871.

Lewis WJ, Stapel JA, Cortesero AM and Takasu K. (1998) Understanding how parasitoids balance food and host needs: importance to biological control. Biol. Cont. 11: 175-183.

Mashal S, Agamy E, Abou-bakr H, Abd El-Wahab TE and El behery H. (2019) Effect of honeybee products, as food supplements, on the biological activities of three Trichogramma species (Hymenoptera: Trichogrammatidae) Egyp. J. Biol. Pest Cont. 29: 46.

Mitsunaga T, Shimoda T and Yano E. (2004) Influence of food supply on longevity and parasitization ability of a larval endoparasitoid, Cotesia plutellae (Hymenoptera: Braconidae). Appl. Entomol. Zool. 39: 691-697.

Munir S, Dosdall LM and Keddie A. (2018) Selective effects of floral food sources and honey on lifehistory traits of a pest-parasitoid system. Ent. Exp. Appl. 166: 500-507.

Sato M and Takasu K. (2000) Food odor learning by both sexes of the pupal parasitoid Pimpla alboannulatus Uchida (Hymenoptera: Ichneumonidae). J. Insect Behav. 13: 263-272.

Siekmann G, Keller MA and Tenhumberg B. (2004) The Sweet Tooth of Adult Parasitoid Cotesia rubecula: Ignoring Hosts for Nectar? J. Insect. Behav. 17: 459476.

Stapel JO, Cortesero AM, De Moraes CM, Tumlinson JH and Lewis WJ. (1997) Extrafloral nectar, honeydew, and sucrose effects on searching behavior and efficiency of Microplitis croceipes (Hymenoptera: Braconidae) in cotton. Environ. Entomol. 26: 617623.

Takasu K and Lewis WJ. (1993) Host and food foraging of the parasitoid Microplitis croceipes: learning and physiological state effects. Biol. Cont. 3: 70-74.
Takasu K and Lewis WJ. (1995) Importance of adult food sources to host searching of the larval parasitoid Microplitis croceipes. Biol. Cont. 5: 25-30.

Wäckers FL. (2005) Suitability of (Extra-) floral nectar, pollen, and honeydew as insect food sources. In: Wäckers, F.L., van Rijn, P.C.J., Bruin, J. (Eds.), Plantprovided food for carnivorous insects: a protective mutualism and its applications, Cambridge university press, UK, pp. 17-74.

Wäckers FL and Steppuhn A. (2003) Characterizing nutritional state and food source use of parasitoids collected in fields with high and low nectar availability. IOBC WPRS Bulletin 26: 203-208.

Wäckers FL and Swaans CPM. (1993) Finding floral nectar and honeydew in Cotesia rubecula: random or directed? Proc. Exp. Appl. Entomol. 4: 67-72.

Wäckers FL, Björnsen A and Dorn S. (1996) A comparison of flowering herbs with respect to their nectar accessibility for the parasitoid Pimpla turionellae. Proc. Exp. Appl. Entomol. 7: 177-182.

Wäckers FL. (1999) Gustatory response by the hymenopteran parasitoid Cotesia glomerata to a range of nectar and honeydew sugars. J. Chem. Ecol. 25: 2863-2877.

Wäckers FL. (2004) Assessing the suitability of flowering herbs as parasitoid food sources: flower attractiveness and nectar accessibility. Biol. Cont. 29: 307-314.

Wade MR, Hopkinson JE and Zalucki MP. (2008 a) Influence of food supplementation on the fitness of two biological control agents: a predatory nabid bug and a bollworm pupal parasitoid. J. Pest Sci. 81: 99107.

Wade MR, Zalucki MP, Wratten SD and Robinson KA. $(2008$ b) Conservation biological control of arthropods using artificial food sprays: current status and future challenges. Biol. Cont. 45: 185-199.

Winkler K, Wäckers F, Bukovinszkine-Kiss J and van Lenteren J. (2006) Sugar resources are vital for Diadegma semiclausum fecundity under field conditions. Basic Appl. Ecol. 7: 133-140.

Witting-Bissinger BE, Orr DB and Linker HM. (2008) Effects of floral resources on fitness of the parasitoids Trichogramma exiguum (Hymenoptera: Trichogrammatidae) and Cotesia congregata (Hymenoptera: Braconidae). Biol. Cont. 47: 180-186.

Wyckhuys KAG, Strange-George JE, Kulhanek CA, Wäckers FL and Heimpel GE. (2008) Sugar feeding by the aphid parasitoid Binodoxys communis: how does honeydew compare with other sugar sources? J. Insect Physiol. 54: 481-491. 
Zhou Z, Rains GC and Kulasiri D. (2012) Development of a behavior 664 parameter in classically conditioned parasitic wasps that detect changes in odor intensity. Trans. Biol. Eng. 5: 19-31.
Zobelein G. (1955) Der Honigtau als Nahrung der Insekten. Teil I. Z. Ang. Ent. 38: 369-416. 